11

\title{
Антистоксова люминесценция в углеродных материалах
}

\author{
() С.Ш. Рехвиашвили ${ }^{1}$, Д.С. Гаев ${ }^{2}$, 3.Ч. Маргушев ${ }^{3}$ \\ ${ }^{1}$ Институт прикладной математики и автоматизации КБНЦ РАН, \\ 360000 Нальчик, Россия \\ ${ }^{2}$ Кабардино-Балкарский государственный университет им. Х.М. Бербекова, \\ 360004 Нальчик, Россия \\ ${ }^{3}$ Институт информатики и проблем регионального управления КБНЦ РАН, \\ 360002 Нальчик, Россия \\ e-mail: rsergo@mail.ru
}

Поступила в редакцию 20.07.2021 г.

В окончательной редакции 16.08.2021г.

Принята к публикации 18.08.2021 г.

\begin{abstract}
Экспериментально исследовано ИК лазерно-индуцированное излучение углеродных материалов. Обнаружены широкополосные спектры излучения в видимой области, а также красное смещение спектров дисперсных углеродных материалов относительно спектров массивного поликристаллического графита. Все измеренные спектры типичны для некогерентного дипольного излучения. Широкополосное излучение качественно объясняется комбинационным рассеянием фотонов.
\end{abstract}

Ключевые слова: антистоксова люминесценция, широкополосное излучение, дипольное излучение, углеродные материалы, размерный эффект.

DOI: $10.21883 /$ OS.2021.12.51747.2560-21

\section{Введение}

Известно, что тепловое излучение можно рассматривать как газ невзаимодействующих фотонов [1]. По определению абсолютно черное тело должно поглощать все падающие на него фотоны независимо от их частоты. Внутри тела фотоны взаимодействуют с ионами и электронами, что приводит к выделению тепла и нагреву. Внутренняя энергия тела не может возрастать бесконечно, поэтому вследствие закона сохранения энергии тело должно не только поглощать фотоны, но излучать их. Причем в отсутствие рассеяния и флуоресценции частоты испущенных и поглощенных фотонов должны совпадать. В результате огромного количества актов поглощения и испускания устанавливается термодинамическое равновесие фотонного газа с телом. Когда внутренняя энергия тела расходуется на флуоресценцию, общее количество фотонов во всей системе может не сохраняться. Это осуществляется, например, по причине „объединения“ двух и более низкочастотных фотонов в один высокочастотный фотон с большей энергией (так называемая ап-конверсия). Если тело обладает указанным свойством, то в нем происходит нелинейное преобразование ИК излучения в видимую антистоксову люминесценцию.

Для сплошного абсолютно черного тела характерна полная изотропия излучения, когда из каждого элемента объема фотоны испускаются равномерно во все стороны. Однако данное свойство нарушается, если тело имеет пространственно-неоднородную структуру. Прежде всего это относится к таким материалам, размеры отдельных структурных элементов которых сопоставимы или меньше длины волны падающих фотонов. Типичные примеры - пористый графит [2-5] и графеновая пена [6-10], которые имеют естественную фрактальную структуру. Эти материалы хотя и очень похожи на абсолютно черное тело, но говорить о локальной изотропии теплового излучения для них уже, очевидно, нельзя. В этих материалах наблюдаются размерные эффекты, вызванные квантовым конфайнментом электронов $[11,12]$ и оптических фононов [13]. Следовательно, излучение в наноматериалах, близких по своим оптическим свойствам к абсолютно черному телу, должно формироваться в результате диссипативной самоорганизации фотонов и всех внутренних подсистем элементарных возбуждений. Вследствие высокой поглощательной способности в ИК диапазоне в таких материалах можно ожидать температурно-активированную антистоксовую люминесценцию.

В [14-16] экспериментально исследовались лазерный нагрев и излучение образцов с углеродными нанотрубками. Было обнаружено, что слабое лазерное воздействие (интенсивность $10^{3} \mathrm{~W} / \mathrm{cm}^{2}$ ) приводит к достаточно сильному свечению образцов [14]. В одинаковых условиях такое же излучение у объемного графита и аморфного углерода не наблюдалось. Интенсивность излучения ожидаемо возрастает с увеличением интенсивности лазерного излучения. Кроме того, влияние оказывает внешняя атмосфера, в особенности кислород [16]. Увеличение давления воздуха приводит к уменьшению интенсивности вторичного излучения. При указанном выше значении интенсивности лазерного излучения и давлении 1000 Ра вторичное излучение практически исчезает, что объясняется усилением конвективного теплообме- 
на. После отключения лазера интенсивность излучения убывает согласно экспоненциальному закону. Высокоэффективный нагрев нанотрубок авторы [14] связывают с малым количеством каналов рассеяния тепла и низкой теплоемкостью нанотрубок. Измеренные в [14-16] широкие и сплошные спектры соответствуют излучению абсолютно черного тела при температурах 1200-2500 K.

Излучение графеновой пены и графеновой керамики изучалось в [17-19]. Результаты этих работ во многом похожи на те, которые были получены для нанотрубок. Показано, что область свечения ограничивается размерами фокального пятна. С увеличением интенсивности внешнего лазерного излучения интенсивность вторичного излучения образцов сначала экспоненциально возрастает, а затем достигает насыщения. Как и для нанотрубок, наблюдается зависимость интенсивности излучения от давления внешней атмосферы. При высоких значениях интенсивности внешнего лазерного излучения зафиксированы широкие полосы как видимого, так и инфракрасного вторичного излучения.

Представления о механизме широкополосного излучения углеродных материалов и наноматериалов до сих пор носят дискуссионный характер. Настоящая работа посвящена решению этой проблемы. Поставлены и выполнены следующие задачи: 1) в одних и тех же условиях измерены спектры излучения массивного поликристаллического графита и углеродных материалов с различной степенью дисперсности; 2) предпринята попытка дать физическую интерпретацию экспериментальным результатам на основе понятий некогерентного дипольного излучения и антистоксовой люминесценции.

\section{Методика эксперимента}

В качестве материалов для экспериментов использовались цилиндрические графитированные электроды марки ЭГСП-1 и технический углерод N220. Характеристики этих материалов следующие. Графитированные электроды: удельное электрическое сопротивление $5.5 \cdot 10^{-6} \Omega \cdot \mathrm{m}$; плотность $1.65 \mathrm{~g} / \mathrm{cm}^{3}$. Технический углерод: размер частиц $20-35 \mathrm{~nm}$; удельная поверхность $1.14 \cdot 10^{5} \mathrm{~m}^{2} / \mathrm{kg}$; насыпная плотность $0.355 \mathrm{~g} / \mathrm{m}^{3}$; удельное электрическое сопротивление $2 \cdot 10^{-3} \Omega \cdot \mathrm{m}$. Материал графитированных электродов исследовался как в массивном виде, так и в механически измельченном до размера частиц менее $1 \mu \mathrm{m}$. Часть образцов помещалась в стеклянные ампулы, вакуумированные и отпаянные при остаточном давлении воздуха $\sim 10^{-4}$ Torr. Эксперименты проводились на образцах в вакууме и воздушной атмосфере.

Источником внешнего излучения служил титансапфировый лазер Fusion, генерирующий непрерывное излучение на длине волны $800 \mathrm{~nm}$, диаметр пучка $2 \mathrm{~mm}$. Мощность сигнала на выходе лазера во всех экспериментах составляла $0.3 \mathrm{~W}$. Мощность контролировалась на выходе лазера прибором S142C. Пучок фокусировался с
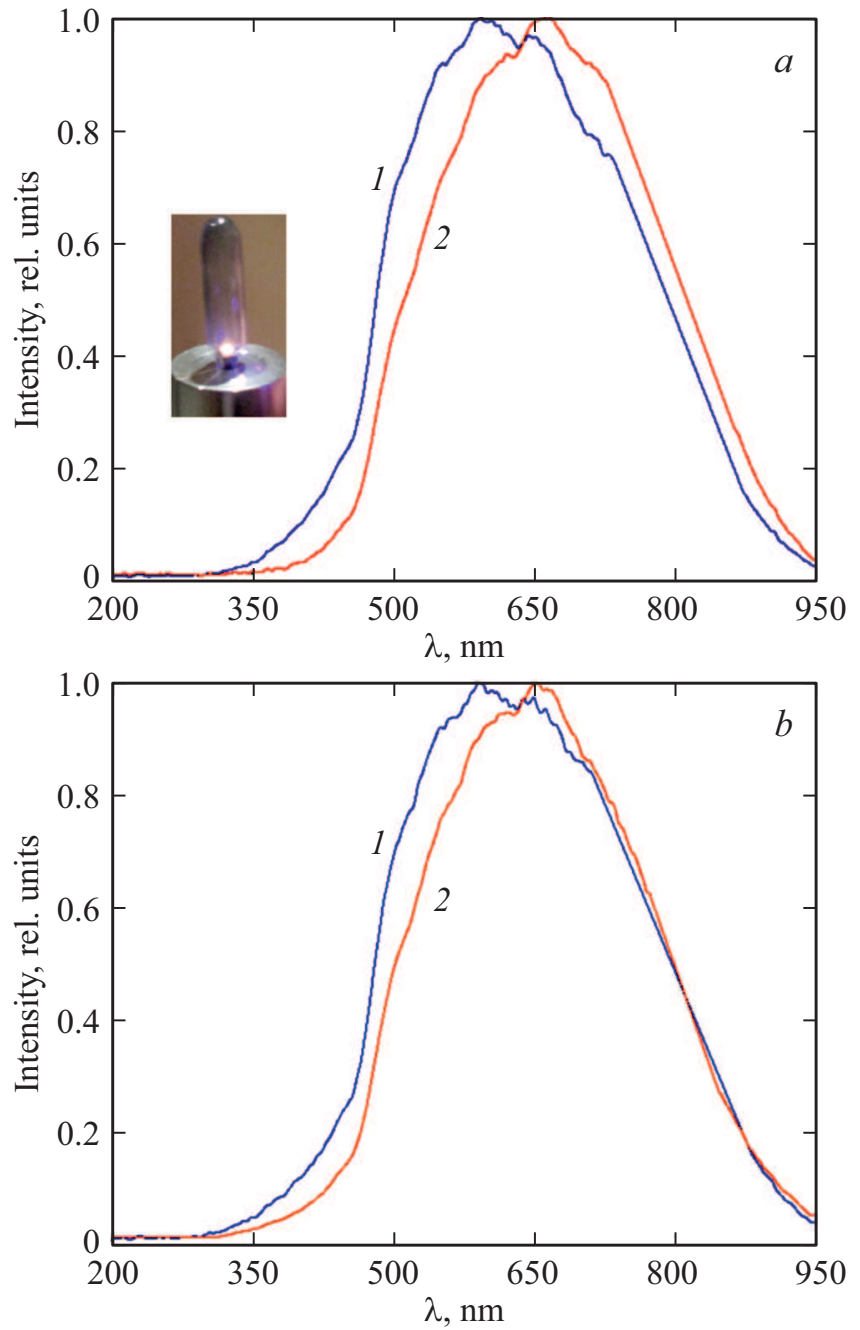

Рис. 1. Спектры излучения углеродных материалов: массивного поликристаллического графита $(1)$ и технического углерода $(2)$ в вакууме $(a)$ и на воздухе $(b)$.

помощью асферической линзы в пятно диаметром $4 \mu \mathrm{m}$. Облучаемый участок образца помещался точно в фокальное пятно линзы. В итоге интенсивность излучения составляла $2.4 \cdot 10^{6} \mathrm{~W} / \mathrm{cm}^{2}$. Спектры излучения регистрировались спектрометром HR4000 с волоконным входом.

На рис. 1 приведены спектры излучения, подвергнутые вычитанию полосы с максимумом на $800 \mathrm{~nm}$, относящейся к релеевскому рассеянию, и медианному сглаживанию. Кривые 1 и 2 относятся к массивным и дисперсным образцам соответственно. Спектры излучения поликристаллического графита в воздушной атмосфере при пониженной интенсивности лазерного воздействия приведены на рис. 2 без математической обработки. Спектры технического углерода и измельченного поликристаллического графита (кривые 2 на рис. 1,2) практически совпадают, несмотря на значительную разницу в размерах частиц. Яркое свечение и тонкое расщепление спектров в области максимума, которые наблюдаются 


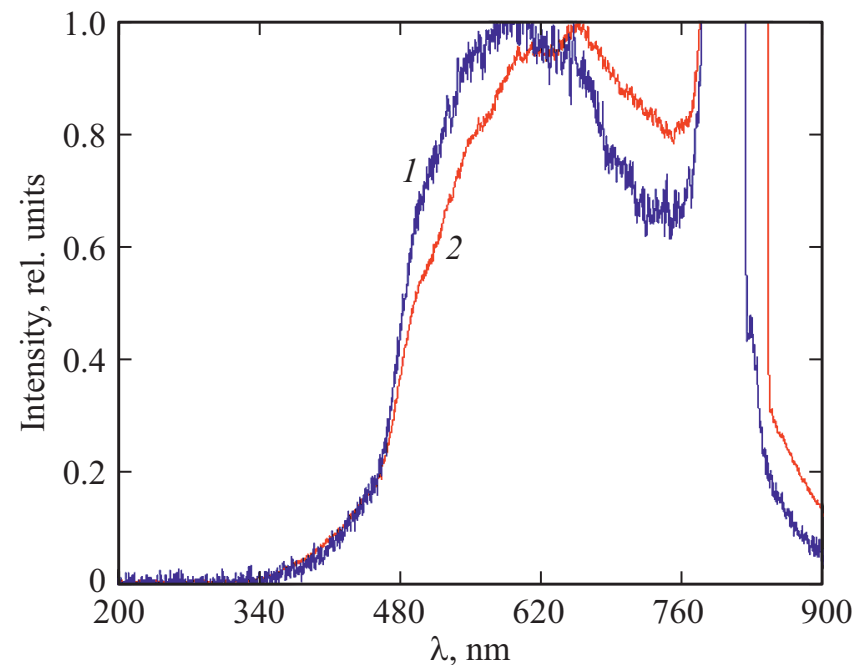

Pис. 2. Спектры излучения поликристаллического графита в воздушной атмосфере при пониженной интенсивности лазерного воздействия: 1 - массивный образец; $2-$ механически измельченный образец. Экспериментальные спектры представлены без математической обработки.

при измерениях в воздушной атмосфере, имеют некоторое сходство с характеристиками галогенных ламп накаливания. При переходе от сплошного материала к дисперсному наблюдается смещение спектра излучения до $60 \mathrm{~nm}$ в длинноволновую область. Спектры излучения дисперсных материалов идентичны спектрам излучения графеновой пены и керамики [17-19].

Чтобы надежно исключить ионизацию материалов, интенсивность лазерного излучения снижалась на три порядка величины путем ослабления накачки лазера и замены фокусирующих линз. Интенсивность вторичного излучения образцов существенно уменьшалась, но форма спектров как в вакууме, так и на воздухе оставалась неизменной (рис. 2).

\section{Результаты и обсуждение}

Необходимо проанализировать вопрос о возможной ионизации использованных углеродных материалов в результате лазерного воздействия. Энергия фотона в наших экспериментах составляла $1.55 \mathrm{eV}$, что меньше первого потенциала ионизации атома углерода $(11.26 \mathrm{eV})$ и работы выхода электрона графита $(4.7 \mathrm{eV})$. Следовательно, однофотонная ионизация в нашем случае однозначно исключена. В процессе непрерывного локального лазерного нагрева происходит остывание за счет рассасывания тепла из области нагрева в объем образца, а также радиационного и конвективного теплообмена. Это делает маловероятной и многофотонную ионизацию, которая, как правило, достигается ультракороткими лазерными импульсами [20]. Спектры свечения углеродной лазерной плазмы содержат узкие пики, соответствующие люминесценции ионов $\mathrm{C}^{+}$и радикалов $\mathrm{C}_{2}$ [21]. В наших экспериментах получены широкие спектры, в которых такие пики отсутствуют. Наконец, красное смещение спектров излучения, продемонстрированное на рис. 1,2, не находит очевидного объяснения, если исходить только из предположения об ионизации материалов.

В широком диапазоне интенсивностей внешнего излучения $10^{4}-10^{7} \mathrm{~W} / \mathrm{cm}^{2}$ наблюдается лазерная абляция графита без образования плазмы [22-24]. Но ввиду большого значения теплоты сублимации (теплота испарения жидкого углерода $360 \mathrm{~kJ} / \mathrm{mol}$ [22], теплота сублимации графита $780 \mathrm{~kJ} / \mathrm{mol}[25])$ количество пара атомов углерода в режиме непрерывного лазерного воздействия, повидимому, невелико [26]. Испарение и люминесценция в режиме непрерывного лазерного воздействия приводят к эффективному охлаждению образцов [27]. В результате на всех спектрах отсутствует планковская составляющая. Из проведенных экспериментов также следует, что при красном смещении в пределах точности измерений добротность, равная отношению собственной частоты колебаний системы к ширине испускаемой спектральной линии, остается неизменной.

Экспериментальные результаты настоящей работы, а также часть результатов из [14-19,28] указывают на антистоксову люминесценцию углеродных материалов. Эти материалы хорошо восприимчивы к лазерному нагреву из-за высоких значений поглощательной способности; за короткое время в них происходит накопление тепловой энергии, а затем преобразование этой энергии в антистоксовую люминесценцию. Диаграмма Фейнмана процесса показана на рис. 3. На начальном этапе поглощается внешний фотон с энергией $\hbar \omega_{P}$ и образуется экситон с промежуточным состоянием $\left|\psi_{a}\right\rangle$. Далее экситон поглощает фонон с энергией $\hbar \omega_{V}$ и переходит в другое квантовое состояние $\left|\psi_{b}\right\rangle$. После этого электрон-дырочная пара совершает излучательную рекомбинацию из состояния $\left|\psi_{b}\right\rangle$, испуская рассеянный фотон с энергией $\hbar \omega_{S}$. Этот процесс может охватывать также синглет-триплетное расщепление экситонных уровней и дополнительные переходы между высокоэнергетическими экситонными уровнями, что отвечает уширению пиков люминесценции на рис. 1,2. Представляет большой интерес сопоставить спектры люминесценции с антистоксовыми полосами рамановского рассеяния на массивном и дисперсном графите. Однако последние в известной нам литературе отсутствуют, а их эксперимен-

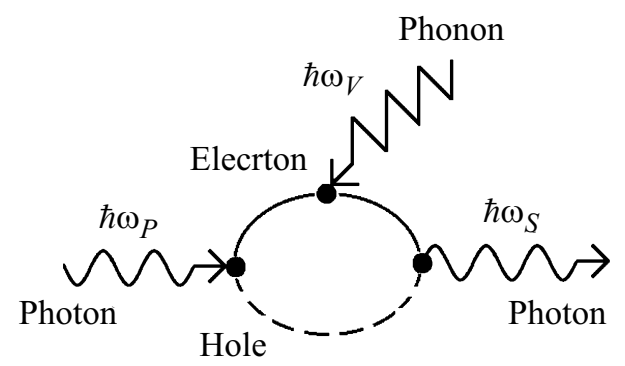

Pис. 3. Диаграмма Фейнмана антистоксовой люминесценции. 
тальное исследование является предметом отдельной работы.

Внешняя световая волна индуцирует электрический дипольный момент, что обусловлено переходом из одного квантового состояния в другое с участием электронной и фононной подсистем. Максимумы широкополосных спектров излучения массивных образцов формально соответствуют длинноволновой области спектра поглощения графита, максимуму мнимой части его диэлектрической функции и электронным переходам $\pi \rightarrow \pi^{*}$ с энергией до $5 \mathrm{eV}$ (участки в зоне Бриллюэна $\mathrm{M}-\mathrm{K}$ и $\mathrm{L}-\mathrm{H})$ [29]. При переходе из возбужденного состояния в невозбужденное энергия фононов передается рассеиваемым фотонам, и их частота увеличивается. У этого процесса обнаруживается размерная зависимость: при переходе от массивного углеродного материала к мелкодисперсному происходит красное смещение спектра излучения на одну и ту же величину $\Delta E=\hbar \Delta \omega>0.1 \mathrm{eV}$. Это явление проявляется в макроскопических масштабах и не связано с размерным квантованием в ограниченных электронных системах, в которых, как известно, наблюдается голубое смещение спектров излучения и поглощения. В соответствии с [30] можно заключить, что оно обусловлено уменьшением электрон-фононного взаимодействия и поляризации материала.

\section{Заключение}

В настоящей работе изучены спектры ИК лазерноиндуцированной люминесценции массивных и дисперсных углеродных материалов. Обнаружены широкополосные спектры видимого излучения и красное смещение спектров для дисперсных материалов (технический углерод и механически измельченный поликристаллический графит). Показано, что измеренные спектры характерны для некогерентного дипольного излучения. Сделано и качественно обосновано предположение о тепловом механизме антистоксовой люминесценции. Представляет большой интерес сравнение спектров лазерноиндуцированной люминесценции со спектрами исключительно теплового излучения углеродных материалов или электролюминесценции. Это будет сделано в следующих работах. Результаты исследований могут оказаться полезными для создания высокоэффективных люминофоров на основе углеродных материалов.

\section{Благодарности}

Авторы признательны профессору W. Strek за плодотворное обсуждение результатов данной работы и Рецензенту за весьма ценные замечания.

\section{Конфликт интересов}

Авторы заявляют, что у них нет конфликта интересов.

\section{Список литературы}

[1] Ландау Л.Д., Лифииц Е.М. Статистическая физика. Часть 1. М.: Физматлит, 2002. 616 с.

[2] Es-Souni M., Schopf D., Solterbeck C.-H., Dietze M. // RSC Adv. 2014. V. 4. P. 17748. doi 10.1039/c4ra00716f

[3] Deng T., Zhou X. // J. Solid State Electrochemistry. 2016. V. 20. P. 2613-2618. doi 10.1007/s10008-016-3260-1

[4] Kang H.G., Jeong Jae-Min., Hong S.B., Lee G.Y., Kim D.H., Kim J.W., Choi B.G. // J. Alloys and Compounds. 2019. V. 770. P. 458-465. doi 10.1016/j.jallcom.2018.08.042.

[5] Greenidge G., Erlebache J. // Carbon. 2020. V. 165. P. 45-54. doi 10.1016/j.carbon.2020.04.028

[6] Chabot V., Higgins D., Yu A., Xiao X., Chen Z., Zhang J. // Energy Environ. Sci. 2014. V. 7. P. 1564-1596. doi 10.1039/C3EE43385D

[7] Ma Y., Chen Y. // National Sci. Rev. 2015. V. 2. N 1. P. 40-53. doi $10.1093 / \mathrm{nsr} / \mathrm{nwu} 072$

[8] Idowu A., Boesl B., Agarwal A. // Carbon. 2018. V. 135. P. 5271. doi 10.1016/j.carbon.2018.04.024

[9] Jia Z., Zhang M., Liu B., Wang F., Wei G., Su Z. // ACS Appl. Nano Mater. 2020. V. 3. N 7. P. 6140-6155. doi $10.1021 /$ acsanm.0c00835

[10] Gao J., Xie D., Wang X., Zhang X., Yue Y. // Appl. Phys. Lett. 2020. V. 117. P. 251901. doi 10.1063/5.0032408

[11] Shang Yuan Ren. Electronic states in crystals of finite size: Quantum confinement of Bloch waves, Springer, 2017. 283 p.

[12] Edvinsson T. // Roy. Soc. Open Sci. 2018. V. 5. P. 180387. doi $10.1098 /$ rsos. 180387

[13] Stroscio M.A., Dutta M. Phonons in nanostructures, Cambridge University Press, 2001. 288 p.

[14] Zeng H., Yang C., Dai J., Cui X. / J. Phys. Chem. C. 2008. V. 112. N 11. P. 4172-4175. doi 10.1021/jp711607n

[15] Lim Z.H., Lee A., Zhu Y., Lim K.-Y., Sow C.-H. // Appl. Phys. Lett. 2009. V. 94. P. 073106. doi 10.1063/1.3083554

[16] Lim Z.H., Lee A., Lim K.Y.Y., Zhu Y., Sow C.-H. // J. Appl. Phys. 2010. V. 107. P. 064319. doi 10.1063/1.3359681

[17] Strek W., Tomala R., Lukaszewicz M., Cichy B., Gerasymchuk Y., Gluchowski P., Marciniak L., Bednarkiewicz A., Hreniak D. // Sci. Rep. 2017. V. 7. P. 41281. doi 10.1038/srep41281

[18] Strek W., Cichy B., Radosinski L., Gluchowski P., Marciniak L., Lukaszewicz M., Hreniak D. // Light: Science \& Applications. 2015. V. 4. P. 237. doi 10.1038/lsa.2015.10

[19] Strek W., Tomala R. // Physica B: Condensed Matter. 2020. V. 579. P. 411840. doi 10.1016/j.physb.2019.411840

[20] Рэди Дж. Действие мощного лазерного излучения. М.: Мир, 1974. 468 с.

[21] Демьяненко А.В., Летохов В.С., Пурецкиий А.А., Рябов Е.A. // Квант. электрон. 1998. Т. 25. № 1. С. 36-40.

[22] Кириллин А.В., Коваленко М.Д., Шейндлин М.А., Живописцев В.С. // Теплофизика высоких температур. 1985. T. 23. № 4. C. 699-706.

[23] Ronchi C., Beukers R., Heinz H., Hiernaut J.P., Selfslag R. // Int. J. Thermophys. 1992. V. 13. P. 107-129. doi $10.1007 / \mathrm{BF} 00503360$

[24] Pflieger R., Sheindlin M., Colle J.-Y. // J. Appl. Phys. 2008. V. 104. P. 054902 . doi $10.1063 / 1.2973666$

[25] Бамарин А.Ю., Лысенко И.Ю., Турчанинов М.А. // Теплофизика высоких температур. 2012. Т. 50. № 4. С. 496-503. doi 10.1134/S0018151X12040037 
[26] Вейко В.П., Либенсон М.Н., Червяков Г.Г., Яковлев Е.Б. Взаимодействие лазерного излучения с веществом. М.: Физматлит, 2008. 312 с.

[27] Петрушкин С.В., Самарцев В.В. Лазерное охлаждение твердых тел. М.: Физматлит, 2005. 224 с.

[28] Shen J., Zhu Y., Chen Ch., Yang X., Li Ch. // Chem. Commun. 2011. V. 47. P. 2580-2582. doi 10.1039/c0cc04812g

[29] Marinopoulos A.G., Reining L., Rubio A., Olevano V. // Phys. Rev. B. 2004. V. 69. P. 245419.

doi 10.1103/PhysRevB.69.245419

[30] Ferrari A.C. // Solid State Commun. 2007. V. 143. P. 47-57. doi 10.1016/j.ssc.2007.03.052 